\title{
EFEK PEMBERIAN JUS BUAH PISANG AMBON (Musa paradisiaca var. sapientum (L.) Kunt.) TERHADAP KADAR GLUKOSA DARAH TIKUS JANTAN GALUR WISTAR YANG TERBEBANI GLUKOSA
}

\author{
Katherine Jessica Ariani, Yunita Linawati*) \\ Fakultas Farmasi, Universitas Sanata Dharma, Yogyakarta, Indonesia
}

Received April 1, 2016; Accepted April 14, 2016

\begin{abstract}
This research is to know the effect of giving Musa paradisiaca var. sapientum (L.) Kunt. juice to the blood glucose levels and to know the most effective of giving Musa paradisiaca var. sapientum (L.) Kunt. dose to lower the blood glucose levels in rats with oral glucose tolerance. This research was experimental study with one way-complete-random design using 25 male rats were divided into five groups. The rats in group I (negative control) were given of CMC 1\%, the group II rats were given $0.64 \mathrm{mg} / \mathrm{kgBW}$ doses of Glibenclamide (positive control), and group III,IV and V were given 5, 10 and 20 $\mathrm{ml} / \mathrm{kgBW}$ doses of Musa paradisiaca var. sapientum (L.) Kunt. juice. The hypoglycemic effect of Musa paradisiaca var. sapientum (L.) Kunt. juice was tested by following the Oral Glucose Tolerance Test (OGTT) method. The blood-glucose contents were taken, at 0 minutes before OGTT, and also taken at minutes of 15, 20, 45, 60, 90, 120, 180, and 240 after OGTT, from the tested animal that had been gotten the pre-treatment of negative control, positive control and Musa paradisiaca var. sapientum (L.) Kunt. juice. The blood glucose levels was determined by using enzymatis GOD-PAP method. The AUC ${ }^{0-240}$ was statistically analyzed using one way ANOVA and Scheffe test with 95\% convidence level. The result of this research showed that Musa paradisiaca var. sapientum (L.) Kunt. can lower on rats in burdened glucose. The effective dose of Musa paradisiaca var. sapientum (L.) Kunt. juice can lower glucose blood levels at $5 \mathrm{ml} / \mathrm{kgBW}$.
\end{abstract}

Keywords: Musa paradisiaca var. sapientum (L.) Kunt. juice, lowering blood

\section{PENDAHULUAN}

Pada masa sekarang ini, di negara-negara maju dan berkembang, usia harapan hidup masyarakat menjadi berkurang karena menurunnya kondisi kesehatan. Masalah kesehatan dan kematian saat ini kebanyakan disebabkan oleh penyakit-penyakit degeneratif diantaranya penyakit jantung koroner, hipertensi, hiperlipidemia dan diabetes mellitus (DM) (Suyono, 2002). Melihat pola pertambahan penduduk saat ini diperkirakan pada tahun 2020 nanti akan ada 178 juta penduduk berusia di atas 20 tahun dan dengan asumsi prevalensi DM sebesar $2 \%$ (terdapat 3,56 juta pasien DM). Antisipasi untuk mencegah dan menanggulangi timbulnya ledakan pasien DM ini harus sudah dimulai dari sekarang (Hiswani, 2011).

DM adalah gangguan metabolisme yang ditandai dengan resistensi terhadap insulin, sekresi insulin tidak cukup, atau keduanya (Wells, Dipiro, Schwinghammer, dan Dipiro, 2009). Penggunaan buah pisang (Musa paradisiaca) merupakan salah satu alternatif pengobatan tradisional untuk menurunkan kadar glukosa darah. Zafar dan Akter (2011) melaporkan bahwa buah pisang (Musa paradisiaca) yang belum matang (unripe) digunakan secara tradisional digunakan untuk mengobati DM dan menurut penelitian yang dilakukan oleh Alarcon-Aguilara et al, (1998) diketahui bahwa buah pisang (Musa paradisiaca L.) memiliki aktivitas antihiperglikemik pada kelinci. Selain itu, penelitian yang pernah dilakukan oleh Nurmaulawati (2004) dan Aenah (2004) menunjukkan bahwa pemberian fraksi larut air ekstrak etanolik dan fraksi etanol ekstrak etanolik pisang kapas (Musa paradisiaca L.) dosis $0,25 \mathrm{~g} / \mathrm{kgBB}$ dapat menurunkan kadar glukosa 
darah tikus jantan galur Wistar yang terbebani glukosa.

Buah pisang (Musa paradisiaca L.) mengandung tannin, alkaloid, saponin dan flavonoid (Eleazu, Okafor, dan Ahamefuna, 2010). Buah pisang ambon (Musa paradisiaca var. sapientum (L.) Kunt.) juga diketahui memiliki kandungan saponin, glikosida, tannin, alkaloid dan flavonoid (Ajani, Salau, Akinlolu, Ekor, dan Soladoye, 2010). Menurut Kaimal, Sujatha, dan George (2010) senyawa yang bertanggung jawab dalam menurunkan kadar glukosa darah adalah flavonoid, tannin, triterpenoid dan steroid. Nakanishi (1974) menyatakan bahwa tumbuhan yang memiliki kandungan senyawa yang sama atau konstituen terkait diduga memiliki khasiat yang sama, sehingga menjadi dasar dilakukannya penelitian ini. Penelitian ini diharapkan mendapatkan informasi mengenai efek buah pisang ambon (Musa paradisiaca var. sapientum (L.) Kunt.) untuk menurunkan kadar glukosa darah dengan menggunakan metode UTGO (Uji Toleransi Glukosa Oral). Penelitian ini menggunakan sediaan jus karena didasarkan pada penggunaan buah pisang ambon (Musa paradisiaca var. sapientum (L.) Kunt.) di masyarakat dan untuk mempertahankan kesegaran, nutrisi, dan kandungan buah pisang ambon (Musa paradisiaca var. sapientum (L.) Kunt.).

\section{METODE PENELITIAN}

Bahan yang digunakan adalah buah pisang ambon yang diperoleh dari Pasar Pakem Yogyakarta. Bahan kimia yang digunakan adalah enzim Glucose GOD FS*(DiaSys ${ }^{\circledR}$, Germany), heparin, glukosa monohidrat p.a $\left(\right.$ Merck $\left.^{\circledR}\right)$, CMC $1 \%$, aquadest, aquabidest, dan parafin cair. Hewan uji yang digunakan yaitu tikus jantan galur Wistar dengan berat badan antara 175-250 g, umur 2-3 bulan dan dalam keadaaan sehat. Alat yang digunakan meliputi alat-alat gelas $\left(\right.$ Pyrex $\left.^{\circledR}\right)$, mortir dan stamper, spuit injeksi peroral, mikropipet, sentrifuge (Hettich WBA SS ${ }^{\circledR}$, Germany), yellow tipe, microtube, Mikrolab 200 Merck dan kuvet, alat timbang elektrik (Mettler Toledo AB 204 ${ }^{\circledR}$, Switzerland), vortex (Janke-Kankel $\mathrm{IKA}^{\circledR}$ Labortechnik), jus ekstraktor, dan stopwatch $\left(\right.$ Olympic $\left.^{\circledR}\right)$.

Buah pisang ambon (Musa paradisiaca var. sapientum (L.) Kunt.) yang digunakan dalam penelitian ini adalah buah yang masih segar dan masih setengah matang (waktu panen 4 bulan). Satu buah pisang ambon setengah matang (100 gram) dibuang kulitnya, kemudian dipotong kecilkecil. Jus buah pisang ambon dibuat dengan jus ekstraktor sehingga didapatkan sari buah pisang ambon $(40 \mathrm{ml})$. Sari buah pisang ambon yang didapat adalah konsentrasi $100 \%$ (tanpa pengenceran).

Sebanyak 25 ekor tikus dibagi secara acak ke dalam 5 kelompok perlakuan masing-masing kelompok 5 ekor tikus. Tiap hewan uji diadaptasikan dengan kondisi yang sama, jauh dari kebisingan dan dihindarkan dari stress. Sebelum mendapat perlakuan, masing masing kelompok dipuasakan selama 10-16 jam dengan tetap diberi minum ad libitum. Kelompok I (kontrol negatif) diberi CMC 1\% $20 \mathrm{ml} / \mathrm{kgBB}$. Kelompok II (kontrol positif) diberi suspensi Glibenklamida 0,64 $\mathrm{mg} / \mathrm{kgBB}$. Kelompok III-V berturut-turut diberi jus buah Musa paradisiaca var. sapientum (L.) Kunt. dengan dosis berturu-turut 5; 10; dan $20 \mathrm{ml} / \mathrm{kgBB}$. Semua pemberian dilakukan secara peroral, selanjutnya dilakukan UTGO 30 menit setelah perlakuan dengan diberikan larutan glukosa monohidrat $15,0 \% \mathrm{~b} / \mathrm{v} ; 1,75 \mathrm{~g} / \mathrm{kgBB}$. Pengambilan cuplikan darah dilakukan sesaat sebelum UTGO sebagai menit ke-0 dan pada menit ke-15, 30, 45, 60, 90, 120, 180, dan 240 setelah UTGO. Pengukuran kadar glukosa darah dilakukan dengan menggunakan metode GOD-PAP. Selanjutnya dibuat kurva UTGO dan perhitungan harga $\mathrm{LDDK}^{0-240}$.

Selanjutnya dibuat kurva dengan mem-plotkan nilai kadar glukosa darah lawan waktu ke-0 sampai menit ke 240 dengan metode trapezoid $\left(\mathrm{LDDK}^{0-240}\right)$ dan rumus yang digunakan adalah sebagai berikut:

$$
L D D K^{t o-t m}=\frac{t_{1}-t_{0}}{2} \times\left(C_{1}+C_{0}\right)+\frac{t_{2}-t_{1}}{2} \times\left(C_{2}+C_{1}\right)+\frac{t_{3}-t_{2}}{2} \times\left(C_{3}+C_{2}\right)+\frac{t_{n}-t_{n-1}}{2} \times\left(C_{n}+C_{n-1}\right)
$$

Keterangan: $\mathrm{t}=$ waktu (jam-1/menit-1); $\mathrm{C}=$ konsentrasi zat dalam darah $(\mathrm{mg} / \mathrm{ml}) ; \mathrm{LDDK}^{\mathrm{to}-\mathrm{tn}}=$ luas daerah di bawah kurva dari waktu ke-0 sampai ke-n 
Tabel I. Rerata Kadar Glukosa Darah dan LDDK $^{0-240} \pm$ SE Setiap Kelompok Perlakuan

\begin{tabular}{|c|c|c|c|c|c|c|}
\hline \multicolumn{2}{|c|}{$\begin{array}{l}\text { Kelompok } \\
\text { Perlakuan } \\
\end{array}$} & $\begin{array}{l}\text { Kontrol (-) } \\
(n=5)\end{array}$ & $\begin{array}{l}\text { Kontrol }(+) \\
(\mathrm{n}=5)\end{array}$ & $\begin{array}{l}\text { Perlakuan I } \\
(n=5)\end{array}$ & $\begin{array}{l}\text { Perlakuan II } \\
(\mathrm{n}=5)\end{array}$ & $\begin{array}{l}\text { Perlakuan III } \\
\quad(n=5)\end{array}$ \\
\hline \multirow{9}{*}{$\begin{array}{c}\text { Rerata } \\
\text { kadar } \\
\text { glukosa } \\
\text { darah } \\
(\mathrm{mg} / \mathrm{dl}) \pm \\
\text { SE }\end{array}$} & 0 & $87,80 \pm 3,12$ & $74,80 \pm 2,56$ & $82,40 \pm 2,98$ & $98,80 \pm 4,43$ & $69,40 \pm 3,08$ \\
\hline & 15 & $150,80 \pm 4,14$ & $101,60 \pm 4,70$ & $105,60 \pm 7,04$ & $112,60 \pm 3,11$ & $98,80 \pm 2,08$ \\
\hline & 30 & $164,20 \pm 1,62$ & $121,40 \pm 1,63$ & $118,00 \pm 3,55$ & $120,60 \pm 2,32$ & $108,60 \pm 3,20$ \\
\hline & 45 & $143,60 \pm 4,33$ & $114,80 \pm 2,06$ & $103,40 \pm 1,17$ & $112,20 \pm 5,09$ & $104,00 \pm 2,92$ \\
\hline & 60 & $126,60 \pm 5,81$ & $95,20 \pm 1,53$ & $101,40 \pm 1,40$ & $108,60 \pm 4,66$ & $101,00 \pm 3,54$ \\
\hline & 90 & $120,00 \pm 5,43$ & $86,00 \pm 0,89$ & $98,00 \pm 1,92$ & $104,40 \pm 4,39$ & $97,60 \pm 4,23$ \\
\hline & 120 & $113,00 \pm 4,17$ & $81,80 \pm 1,39$ & $93,60 \pm 3,14$ & $95,80 \pm 3,88$ & $95,40 \pm 4,35$ \\
\hline & 180 & $105,40 \pm 5,28$ & $74,60 \pm 1,03$ & $92,20 \pm 3,80$ & $90,20 \pm 3,83$ & $87,80 \pm 3,69$ \\
\hline & 240 & $93,2 \pm 60,03$ & $55,20 \pm 2,15$ & $85,40 \pm 2,56$ & $78,60 \pm 1,96$ & $81,60 \pm 3,59$ \\
\hline \multicolumn{2}{|c|}{ LDDK $^{0-240}$} & $29340 \pm 262,10$ & $20327 \pm 1203,70$ & $23670 \pm 796,29$ & $23578 \pm 753,88$ & $22747 \pm 1003,60$ \\
\hline
\end{tabular}

Keterangan:

Kontrol negatif

Kontrol positif

Perlakuan I

Perlakuan II

Perlakuan III
: CMC $1 \%$

: Glibenklamida dosis $0,64 \mathrm{mg} / \mathrm{kgBB}$

: Jus buah pisang ambon $5 \mathrm{ml} / \mathrm{kgBB}$

: Jus buah pisang ambon $10 \mathrm{ml} / \mathrm{kgBB}$

: Jus buah pisang ambon $20 \mathrm{ml} / \mathrm{kgBB}$
Data kadar glukosa darah pada tiap kelompok dianalisis secara statistik. Dari harga LDDK $^{0-240}$ glukosa darah dilakukan uji distribusi menggunakan uji Kolmogorov Smirnov kemudian jika distribusinya normal dilanjutkan dengan analisis One Way ANOVA dan Post Hoc Tests Scheffe dengan tingkat kepercayaan $95 \%$. Jika nilai LDDK ${ }^{0-}$ ${ }^{240}$ glukosa darah mempunyai variansi yang berbeda maka dilakukan uji Kruskal Wallis dan dilanjutkan uji Mann Whitney dengan tingkat kepercayaan 95\% untuk mengetahui perbedaan masing-masing kelompok bermakna (signifikan) $(\mathrm{p}<0,005)$ atau tidak bermakna (tidak signifikan) ( $\mathrm{p}>0,005)$.

\section{HASIL DAN PEMBAHASAN}

Kadar glukosa darah tikus setelah pembeban glukosa yang diikuti dengan perlakuan jus buah pisang ambon dapat terlihat pada Tabel 1 dan Gambar 1. Terlihat bahwa kadar glukosa darah mencapai maksimum pada menit ke- 30 dan kadar glukosa darah mengalami kenaikan pada menit ke15 sampai 90, jika dibandingkan dengan menit ke-0. Hal ini menunjukkan bahwa percobaan ini sudah sesuai dengan teori Mayes, Murray, dan Granner (2000) yaitu kadar glukosa darah secara normal akan meningkat pada satu jam setelah pemberian glukosa oral. Kadar glukosa darah menjadi normal kembali setelah dua sampai tiga jam setelah pemberian glukosa. Ini berarti bahwa tubuh hewan uji berada dalam keadaan normal sehat karena masih dapat mentoleransi pembebanan glukosa secara normal. Pada pemberian jus buah pisang ambon dosis 5, 10 dan $20 \mathrm{ml} / \mathrm{kgBB}$ menujukkan penurunan glukosa darah pada menit ke- 120, 180 dan 240 secara perlahan-lahan.

Hasil uji Post Hoc Scheffe LDDK $^{0-240}$ glukosa darah pada Tabel II menunjukkan bahwa antara kontrol negatif yaitu larutan CMC $1 \%$ dengan kontrol positif yaitu suspensi Glibenklamida 0,64 $\mathrm{mg} / \mathrm{kgBB}$ dan semua perlakuan jus buah pisang ambon memiliki perbedaan yang bermakna $(\mathrm{p}<0,05)$. Hal ini berarti bahwa kontrol positif Glibenklamida dan perlakuan jus buah pisang ambon pada semua peringkat dosis mempunyai efek menurunkan kadar glukosa darah.

Semua kelompok perlakuan jus buah pisang ambon memiliki perbedaan yang tidak bermakna ( $>>0,05)$ terhadap Glibenklamida. Hal ini menunjukkan bahwa jus buah pisang ambon dosis 5,10 , dan $20 \mathrm{ml} / \mathrm{kgBB}$ memiliki efek penurunan kadar glukosa darah yang setara dengan Glibenklamida (kontrol positif) $0,64 \mathrm{mg} / \mathrm{kgBB}$.

Jus buah pisang ambon dosis $5 \mathrm{ml} / \mathrm{kgBB}$ menunjukkan perbedaan yang tidak bermakna ( $\mathrm{p}>0,05)$ terhadap jus buah pisang ambon dosis 10 dan $20 \mathrm{ml} / \mathrm{kgBB}$. Hal yang sama juga terlihat pada 
pemberian jus buah pisang ambon 10 dan 20 $\mathrm{ml} / \mathrm{kgBB}$ memberikan perbedaan yang tidak bermakna ( $p>0,05)$. Hal ini berarti bahwa jus buah pisang ambon dosis 5, 10, dan $20 \mathrm{ml} / \mathrm{kgBB}$ memberikan efek yang sama dalam menurunkan kadar glukosa darah. Berdasarkan hasil analisis statistik dapat disimpulkan bahwa jus buah pisang ambon dosis $5 \mathrm{ml} / \mathrm{kgBB}$ merupakan dosis yang efektif dalam menurunkan kadar glukosa darah tikus jantan galur Wistar yang terbebani glukosa. Hal ini dikarenakan pada pemberian jus buah pisang ambon dosis $5 \mathrm{ml} / \mathrm{kgBB}$ yang merupakan dosis terkecil sudah mampu menurunkan kadar glukosa darah yang setara dengan Glibenklamida dosis 0,64 $\mathrm{mg} / \mathrm{kgBB}$. Hasil percobaan pada Tabel 1 menunjukkan nilai LDDK $^{0-240}$ pada kelompok perlakuan dosis $20 \mathrm{ml} / \mathrm{kgBB}$ memiliki nilai LDDK $^{0-240}$ paling kecil (22747) diantara perlakuan jus buah pisang ambon dosis $5 \mathrm{ml} / \mathrm{kgBB}(23670)$ dan dosis $10 \mathrm{ml} / \mathrm{kgBB}$ (23578). Hal ini menunjukkan bahwa semakin besar dosis pemberian jus buah pisang ambon maka efek penurunan kadar glukosa darah semakin besar.

Hasil penelitian yang dilakukan telah sesuai dengan laporan penelitian Zafar dan Akter (2011) yang menyatakan bahwa buah pisang (Musa paradisiaca L.) secara tradisional dapat digunakan untuk menurunkan kadar glukosa darah. Menurut Kaimal et al, (2010) senyawa yang bertanggung jawab dalam menurunkan kadar glukosa darah adalah flavonoid dan tannin. Glikosida flavonoid mampu bertindak sebagai penangkap radikal bebas sehingga mencegah aksi diabetogenik. Tanin diketahui dapat memacu metabolisme glukosa, sehingga timbunan glukosa ini dalam darah dapat dihindari. Senyawa ini juga mempunyai aktivitas

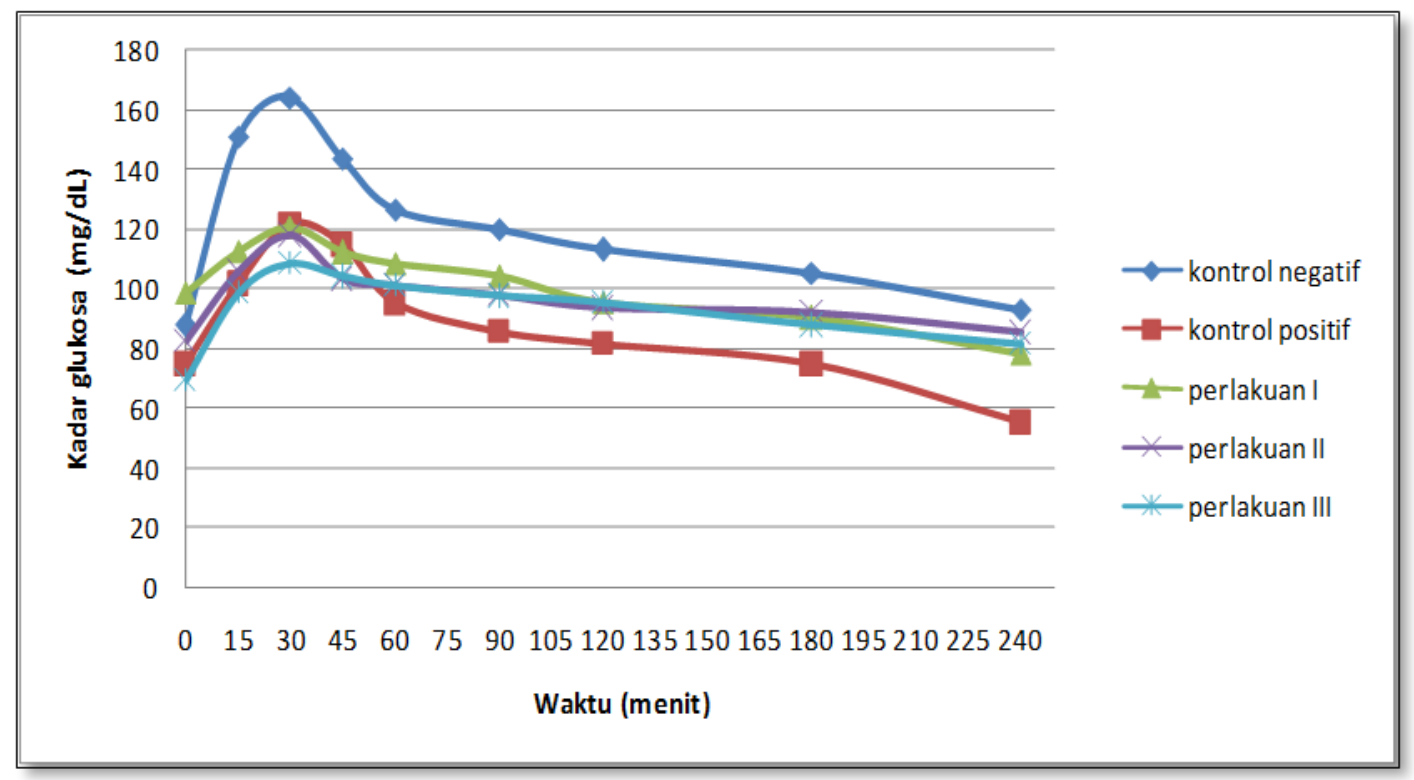

Gambar 1. Kurva hubungan antara waktu dan rerata kadar glukosa darah

Keterangan: Kontrol negatif Kontrol positif : CMC $1 \%$ Perlakuan I

: Glibenklamida dosis $0,64 \mathrm{mg} / \mathrm{kgBB}$

Perlakuan II

: Jus buah pisang ambon $5 \mathrm{ml} / \mathrm{kgBB}$

Perlakuan III

: Jus buah pisang ambon $10 \mathrm{ml} / \mathrm{kgBB}$

: Jus buah pisang ambon $20 \mathrm{ml} / \mathrm{kgBB}$ 
Jurnal Farmasi Sains dan Komunitas, 2016, 13(1), 1-6

Tabel II. Hasil Uji Post Hoc Scheffe LDDK ${ }^{0-240}$ Glukosa Darah Tikus yang Terbebani Glukosa

\begin{tabular}{cccccc}
\hline & 1 & 2 & 3 & 4 & 5 \\
\hline 1 & - & BB & BB & BB & BB \\
\hline 2 & BB & - & BTB & BTB & BTB \\
\hline 3 & BB & BTB & - & BTB & BTB \\
\hline 4 & BB & BTB & BTB & - & BTB \\
\hline 5 & BB & BTB & BTB & BTB & - \\
\hline
\end{tabular}

Keterangan :

1 : Kontrol negatif CMC $1 \%$

2 : Kontrol positif glibenklamida dosis $0,64 \mathrm{mg} / \mathrm{kgBB}$

3 : Jus buah pisang ambon dosis $5 \mathrm{ml} / \mathrm{kgBB}$ (perlakuan I)

4 : Jus buah pisang ambon dosis $10 \mathrm{ml} / \mathrm{kgBB}$ (perlakuan II)

5 : Jus buah pisang ambon dosis $20 \mathrm{ml} / \mathrm{kgBB}$ (perlakuan III)

hipoglikemik yaitu dengan meningkatkan glikogenesis. Tanin juga diketahui dapat mengurangi penyerapan glukosa di usus halus, sehingga kadar glukosa darah mengalami penurunan (Dalimarta, 2005). Dapat disimpulkan bahwa efek penurunan kadar glukosa darah oleh jus buah pisang ambon diduga karena adanya kandungan flavonoid dan tannin, karena telah diketahui bahwa buah pisang ambon memiliki kandungan saponin, glikosida, tannin, alkaloid dan flavonoid (Ajani et al, 2010). Berdasarkan hasil penelitian ini, dapat dilakukan penelitian lebih lanjut mengenai ekstraksi dan isolasi kandungan kimia jus buah pisang ambon yang dapat menurunkan kadar glukosa darah.

\section{KESIMPULAN}

Berdasarkan penelitian yang dilakukan dapat disimpulkan bahwa jus buah pisang ambon (Musa paradisiaca var. sapientum (L.) Kunt.) dapat menurunkan kadar glukosa darah pada tikus jantan galur Wistar yang terbebani glukosa. Dosis efektif dari jus buah pisang ambon (Musa paradisiaca var. sapientum (L.) Kunt.) yang dapat menurunkan kadar glukosa darah tikus jantan galur Wistar yang terbebani glukosa adalah dosis $5 \mathrm{ml} / \mathrm{kgBB}$.

\section{DAFTAR PUSTAKA}

Aenah, F., 2004. Pengaruh Pemberian Fraksi Etanol Ekstrak Etanolik Pisang Kapas (Musa paradisiaca L.) Terhadap Kadar Glukosa
Darah Tikus Putih Jantan Galur Wistar (Rattus norvegicus) yang Dibebani Glukosa. Skripsi, Fakultas Farmasi, Univeristas Gajah Mada, Yogyakarta.

Aguilara Alarcon-, F.J., Roman-Ramos, R., PerezGutierrez, S., Aguilar-Contreras, A., Contreras-Weber, C.C., Flores-Saenz, J.L., 1998. Study of The Anti-Hyperglycemic Effect of Plants Used ss Antidiabetics. $J$. Ethnopharmacol, 61, 101-110.

Ajani, E.O., Salau, B.A., Akinlolu, A.A., Ekor, M.N., and Soladoye M.O., 2010. Methanolic Extract of Musa sapientum Suckers Moderates Fasting Blood Glucose and Body Weigth of Alloxan Induced Diabetic Rats. Asian J. Biol. Scl, 1(1), 30-35.

Dalimartha, S., 2005. Ramuan Tradisional Untuk Pengobatan Diabetes Mellitus, cetakan X. Penebar Swadaya, Jakarta, 3-15.

Eleazu, C.O., Okafor, P.N., Ahamefuna, I., 2010. Total Antioxidant Capacity, Nutritional Composition and Inhibitory Activity of Unripe Plantain (Musa paradisiaca) on Oxidative Stress in Alloxan Induced

Diabetic Rabbits. Pakistan Journal of Nutrition, 9 (11), 1052-1057.

Hiswani, 2011. Penyuluhan Kesehatan Pada

Penderita Diabetes Mellitus, Fakultas Kedokteran Universitas Sumatra Utara, Medan. 
Kaimal, S., Sujatha, K.S., George, S., 2010. Hypolipidaemic and Antioxidant Effects of Fruits of Musa AAA (Chenkadali) in Alloxan Induced Diabetic Rats (Ed 48), Indian Journal of Experimental Biology, 165-173.

Mayes, P.A., Murray, R., K., Granner, D., K., 2000. Harper's Biochemistry, 25th, edition, New York: Mc Graw-Hill, 7-10.

Nakanishi, K., 1974. Natural Products Chemistry, vol 1. Kodansha Scientific, Tokyo.

Nurmaulawati, R., 2004. Pengaruh Pemberian Fraksi Larut Air Ekstrak Etanolik Pisang Kapas (Musa paradisiaca L.) Terhadap Kadar Glukosa Darah Tikus Putih Jantan Galur Wistar (Rattus norvegicus) yang Dibebani
Glukosa, Skripsi, Fakultas Farmasi, Univeristas Gajah Mada, Yogyakarta.

Suyono, S., 2002. Patofisiologi Diabetes Mellitus, cetakan ke 2, Fakultas Kedokteran Universitas Indonesia, Jakarta, 7-15.

Wells, B.G., Dipiro, J.T., Schwinghammer, T.L, Dipiro, C.V., 2009. Pharmacotherapy. Handbook, $7^{\text {Th }}$ edition, Mc Graw Hill, New York

Zafar, M.I., Akter, S., 2011. Musa paradisiaca L. and Musa sapientum L.: A Phytochemical and Pharmacological Review. Journal of Applied Pharmaceutical Science, 01(05), 1420. 